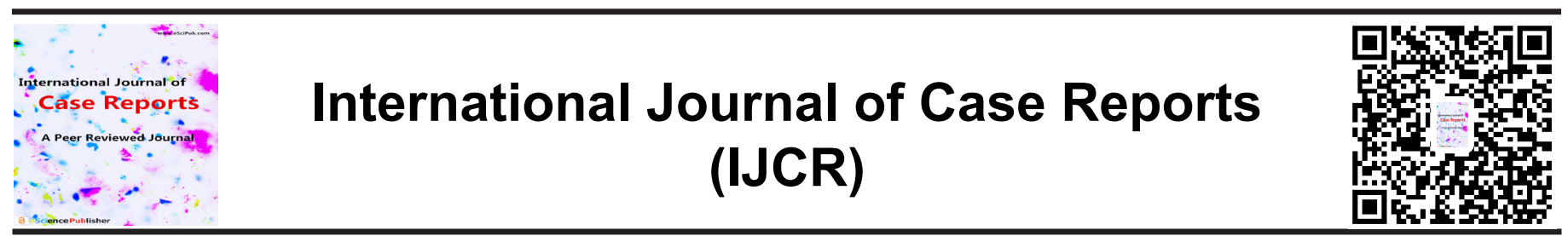

\title{
Sudden Death in African Adult Males: Case Reports and Review of Literatures
}

\begin{abstract}
Ayodele J Omotoso ${ }^{1}$, Lawson Ekpe ${ }^{2}$, Akintunde Akintomide ${ }^{3}$, Patience Odusolu ${ }^{4}$, Martin A Nnoli $^{1}$
\end{abstract}

1,Department of Pathology, University of Calabar, Calabar

2Department of Chemical Pathology, University of Calabar, Calabar

3Department of Radiology, University of Calabar, Calabar

4Department of Obstetrics and Gynaecology, University of Calabar, Calabar

\begin{abstract}
Sudden death is common in Africans especially in males in their middle ages. With increasing evidence in reduction of life expectancy among the populace due to several confounding factors there is need to review some of the causes of sudden unexpected death. The study came from the observation of the authors on autopsy requests and reports in Calabar. Two middle aged *Correspondence to Author: security officers attached to different private homes were found dead on their duty posts on different days. Autopsy reports on them were similar revealing enlarged heart with evidence of myocardial infarction. Other findings include fatty change, pulmonary oedema and contracted kidneys. Hypertensive heart disease is a common disease condition with resultant high morbidity and mortality if not diagnosed early and well managed.

Dr Ayodele Joshua Omotoso, department of pathology, university of Calabar, Calabar, Nigeria ayomemee@yahoo.com, $+2348037134716$

How to cite this article:

Omotoso et al.,. Sudden Death in African Adult Males: Case Reports and Review of Literatures. International Journal of Case Reports, 2017 1:4
\end{abstract}

Keywords: sudden unexpected death, autopsy, heart, cardiomyopathy, hypertension

\section{eSciencePublisher}

eSciPub LLC, Houston, TX USA. Website: http://escipub.com/ 


\section{INTRODUCTION:}

Autopsy ${ }^{1}$ or necropsy is post mortem examination of a body, in other words it is the examination of body after death to ascertain the cause of death, the events surrounding the death, the time of death, the pathomorphological changes in the organs of the deceased or any other factors relating to the deceased. It is often broadly divided into Hospital based autopsy in which death occurred in the course of being treated in the hospital and the medicolegal or coroner autopsy in which inquest is made to ascertain the cause of death weither the death is natural or not.

The first law on coroner autopsies was established in Nigeria in $1944^{2}$ which stated that the death of non-native must be reported to coroner. The law was extended to everyone with circumstantial death in Nigeria in $1958^{3}$. Under section 4 subsection 1 of the coroner's law CAP 131of the Federation of Nigeria and Lagos, Magistrates are empowered to conduct inquests on any suspicious death in his or her jurisdiction.

Several studies in Nigeria and across the globe showed that cardiac cause is the most predominant cause of sudden unexpected death ${ }^{4,5,6,7,8}$. Most cases showed male predominance while the rate is significantly higher in the northern part of Nigeria ${ }^{6}$. Molecular study is said to be able to explain some of the unexplained cardiac death ${ }^{10}$. Despite overwhelming evidence of cardiac, there are other evidence showing that communicable disease should not be overlooked because they are becoming more prominent ${ }^{11}$.

This study is first of its kind showing related cases of sudden death among people in developing country due to cardiac case. This is to increase the body of evidence and to review other literature on same case.

\section{MATERIAL AND METHOD}

This is a study of two cases of autopsy done on patients with similar occupation and similar autopsy reports in Calabar, Cross River state of Nigeria.

\section{Case report: 1}

A 48 year-old security officer attached to a private property was found dead on duty. He was a known alcoholic but with no medical history. The autopsy showed a middle aged man, anicteric with no palor. The heart was enlarged weighing $650 \mathrm{~g}$, with opaque thickened valves and the mitral valve show button fish appearance. There were atheromatous plaques on the major vessels especially the abdominal aorta while the coronary vessels showed $2 / 3$ obstruction. The liver weighed $2300 \mathrm{~g}$ with smooth glittery yellowish external surface. The cut surface showed fatty change. Both kidneys appeared shrunken. There was pulmonary oedema with evidence of lobar pneumonia.

\section{Case report: 2}

A 41 year old security officer attached to a private apartment was found dead at the duty post. There was past history of alcohol consumption and smoking. He was diagnosed with congestive cardiac failure and was on medication before his demise. Previous chest X-ray report shows cardiomegaly and unfolding of the aorta. The autopsy revealed an enlarged heart and liver with biventricular thickness. There are artheromatous plaques on the ascending, descending and abdominal aorta. The lungs were heavy with frothy fluid. The kidneys were shrunken and granular with evidence of shocked kidney characterized by distinct corticomedullary differentiation.

\section{DISCUSSION:}




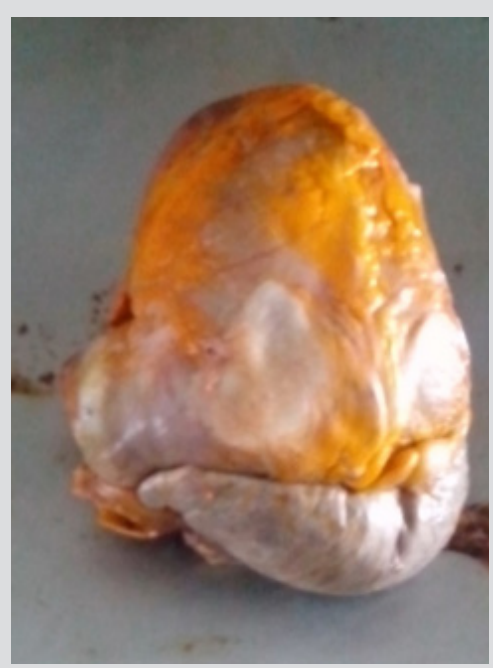

Figure I: Section shows an enlarged heart weighing $650 \mathrm{~g}$

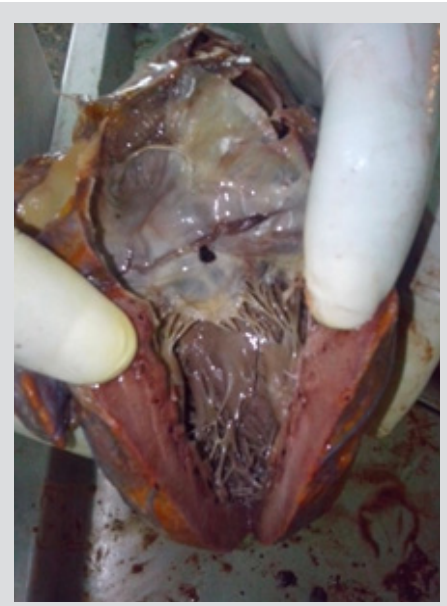

Figure II: Section showing hypertrophy left ventricular wall thickness, thickened and opaque valve with shortened cordea tendinea and thickened papillary muscle.

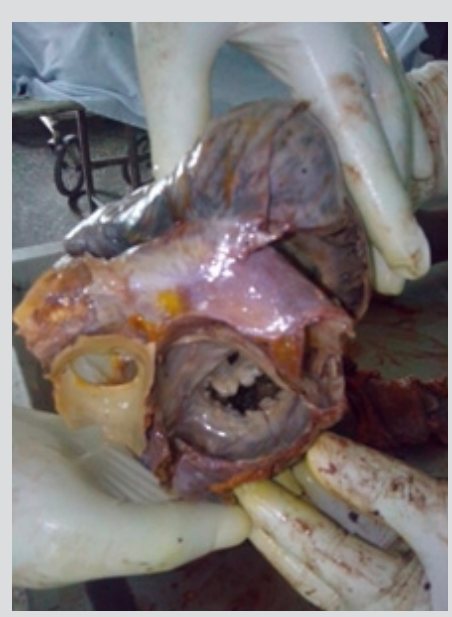

Figure III: Mitral valve with 'button hole' appearance. 
A study done by Rotimi et al at lle - Ife, Nigeria showed the prevalence of sudden cardiac death (SCD) among medicolegal autopsy to be $3.1 \%{ }^{4}$. The male to female ratio was 3:1 with age prevalence of 52 years. Another study by Oberaifo et al at Benin city on coronal cases have a similar sex distribution of 3.7:1 but younger age prevalence of 20-29 years. Accidental death was the commonest cause of death among these individuals $^{5}$. On the other hand Mandong et al ${ }^{6}$ studied 279 cases of medicolegal autopsies in the North central part of Nigeria in which there was higher male preponderance; the male: female ratio was 4.5:1. This high incidence compare to studies from Ife and Benin may be due largely to the cultural setting in the Northern part of Nigeria that tends to keep women in the house. Accidental deaths accounted for $51 \%$ of the cases while homicide and sudden death were $36 \%$ and $13 \%$ respectively. This is similar to the Benin experience. Cardiovascular deaths were responsible for $63 \%$ of all sudden natural death with Male: Female ratio of $6: 1.46 \%$ of these cases were from hypertensive heart disease, $32 \%$ from cerebrovascular accident, 13.6 from pulmonary embolism and 9\% from myocardial infarction. A case of myocardial infarction was seen to have died during sexual intercourse. In the cases reported the patients were both male, one was been managed for hypertensive heart disease while the other fellow had no history of hypertension. The causes of death were both related to hypertension.

Akhiwu et al reported a prevalence of $27.3 \%$ as death classified as sudden unexpected death (SUD) from cardiovascular disease among elderly in Benin, Nigeria ${ }^{7}$. In a further study and review of 50 autopsies by Rotimi et $\mathrm{al}^{8}$ in cases of SUD from cardiac causes in Nigeria; it was discovered that death was due to hypertensive heart disease in $82 \%$ of cases with only $18 \%$ of cases been previously diagnosed. Acute left ventricular failure was the commonest; accounting for $68 \%$ cause of death while $4 \%$ was from acute myocardial infarction secondary to coronary artery disease.

Lemonte $^{9}$ et al further emphasis the role of cardiac death with a study on 43 deaths (medicolegal autopsies) following stressful event. The study showed male: female ratio of $2: 1$ and $90 \%$ of the patient had no previous clinical history of cardiovascular disease but $88.4 \%$ of the cases had cardiac cause of death. $71 \%$ of the patients had coronary heart disease, $15.8 \%$ had cardiomyopathy, $7.9 \%$ with right ventricular dysplasia and $5.3 \%$ aortic valvular stenosis. It was concluded that stress related sudden death occur primarily in those with severe heart disease and this is the case with those presented. However, Tester $^{10}$ et al showed that molecular study may be able to explain autopsies in unexplained sudden cardiac death.

\section{CONCLUSION:}

Hypertension continues to rank highest among the causes of sudden unexpected death in our populace. There is need for continual sensitization and increase of awareness of our community for early detection and proper management of this condition. The security officers should be medically certified before employed into homes.

\section{REFERENCE:}

1. Bhulhar DS, Gorea RK, Aggarwal AD. Medicolegal autopsy panel of doctors. Present scenario. JIAFM 2004; 26: 971-3

2. Coroners Act of 1945, Laws of the federation of Nigeria and Lagos, Cap 41

3. Coroner Act of 1958, laws of the Federation of Nigeria and Lagos, Cap 41

4. Rotimi O, Fatusi AO, Odesanmi WO Sudden 


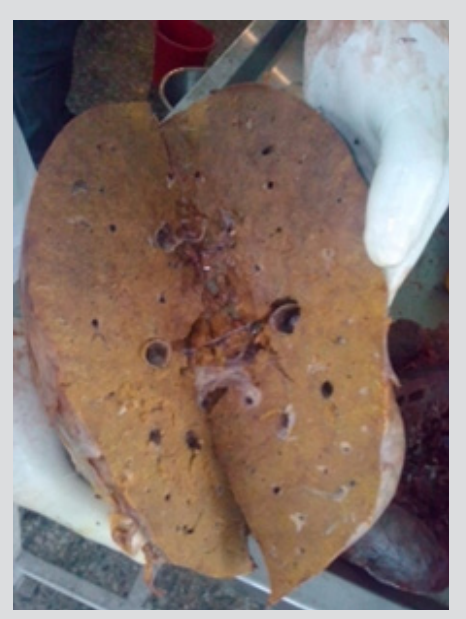

Figure IV: Section showing the massive yellowish coloration of the liver

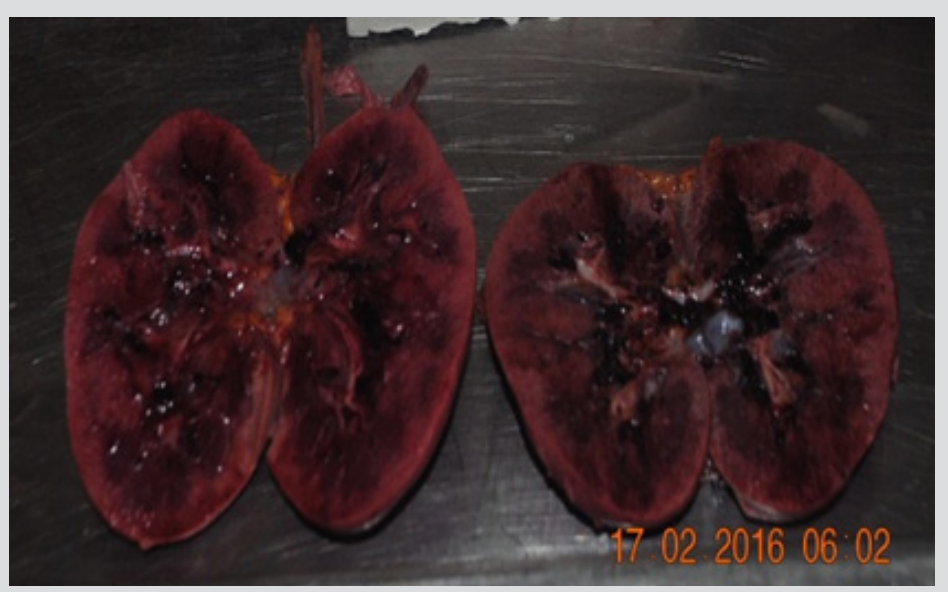

Figure V: Section showing shocked kidneys

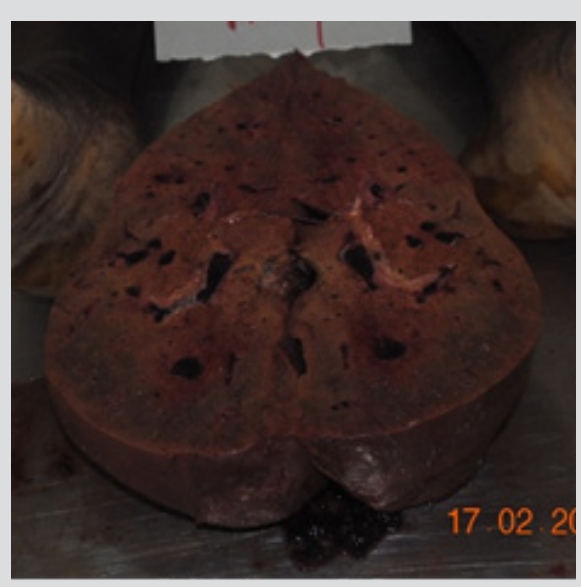

Figure Vl: section showing enlarged liver with congestion 


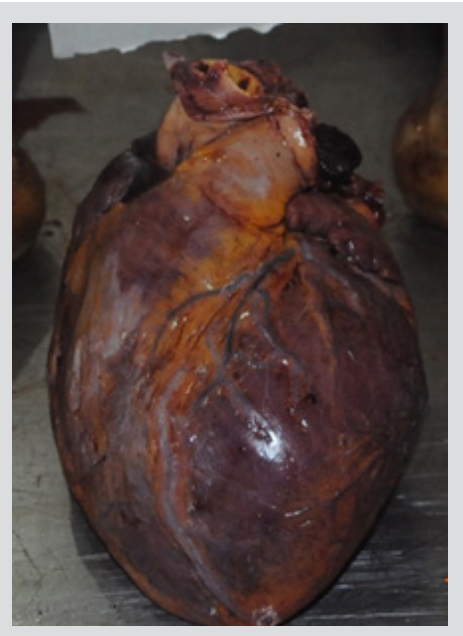

Figure Viii: section showing enlarged and globular heart

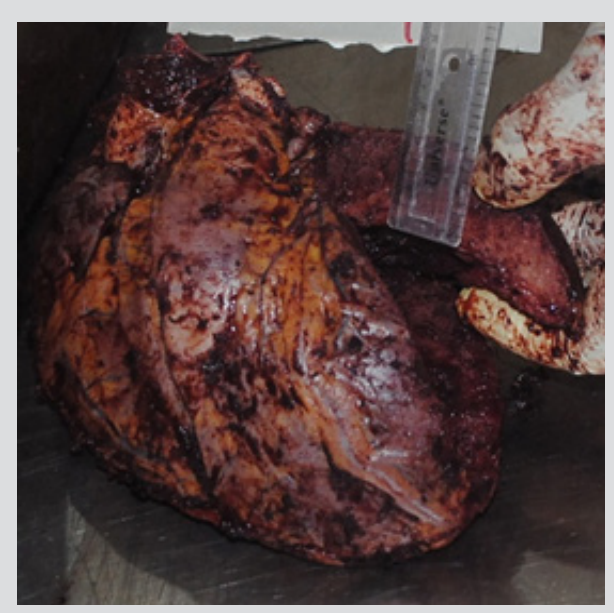

Figure IX: section showing ventricular wall thickness

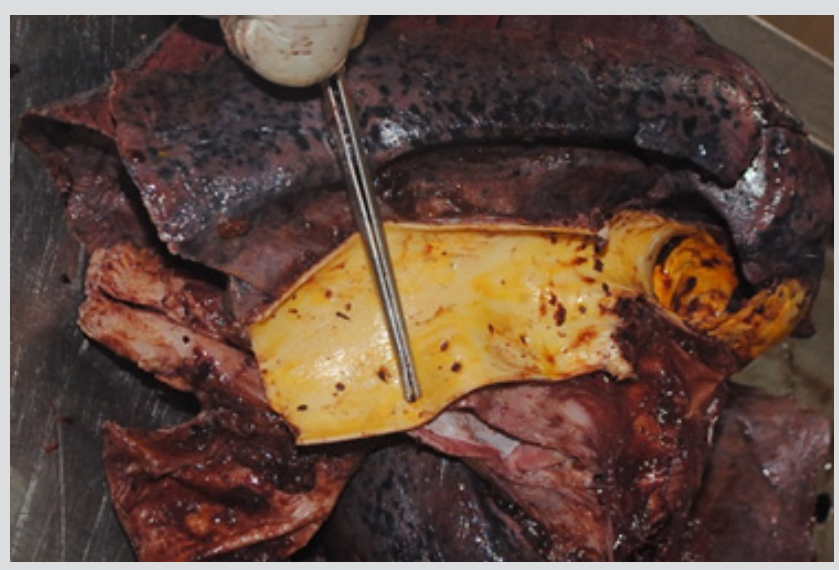

Figure X: section showing artheromatic plaque in the descending aorta 
cardiac death in Nigerians--the Ile-Ife experience West Afr J Med. 2004 Jan-Mar;23(1):27-31.

5. Oberaifor AW, Nwaifor CC. Coroner autopsies originating from complaits to the police in a Nigerian Urban centre. Kasr Ainy Med J 2015; 21: $11-5$

6. Mandong BM, Manasseh AN, Ugwu BT Medicolegal autopsies in North Central Nigeria. East Afr Med J. 2006 Nov;83(11):626-30.

7. Akhiwu WO, Igbe AP Deaths with medicolegal implications in the elderly: experience from Benin City, Nigeria. Asian J Gerontol Geriatr 2011; 6: 35-7

8. Rotimi $\mathrm{O}^{1}$, Ajayi AA, Odesanmi WO Sudden unexpected death from cardiac causes in Nigerians: a review of 50 autopsied cases. Int J Cardiol. 1998 Jan 31;63(2):111-5.

9. Lecomte D, Fomes P, Nicolas G. stressful events as a trigger of sudden death; a study of 43 medicolegal autopsy cases. Forensic sci Int 1996 May 17, 79 (11): 1-10

10. Tester DJ, Ackerman MJ. The role of molecular autopsy in unexplained sudden cardiac death. Curr open cardiolo 2006 May; 21 (3):166-72

11. Patience Olayinka Akinwusi, Akinwumi Oluwole Komolafe, Olanrewaju Olayinka Olayemi, Adeleye Abiodun Adeomi. Communicable disease-related sudden death in the 21st century in Nigeria. Infect Drug Resist. 2013; 6: 125-132

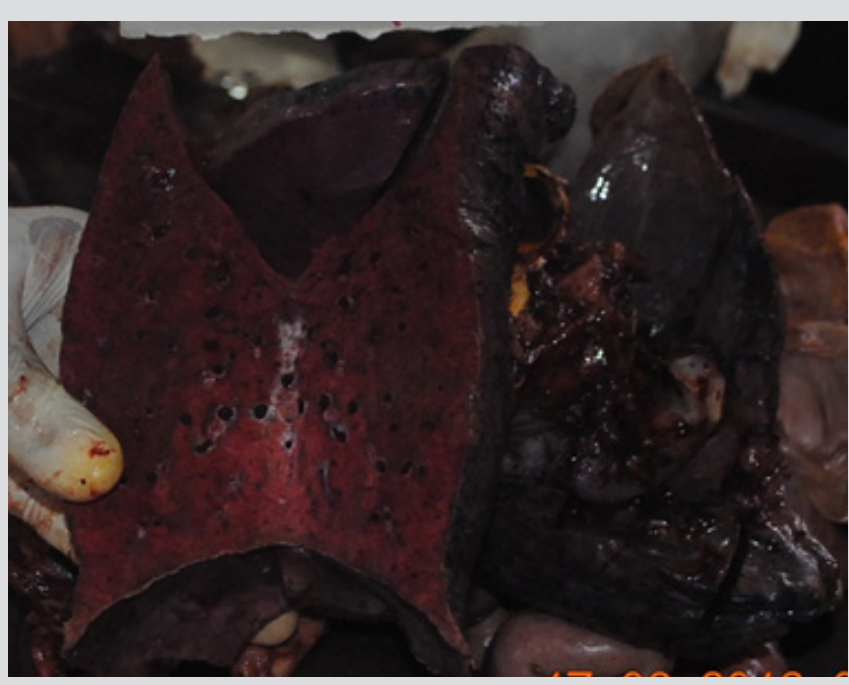

Figure XI: section showing frothy fluid in the lung 